\title{
Screening of Selected Rice Varieties and Advanced Breeding Lines against Iron Toxicity under Field Conditions in the Low Country Wet Zone of Sri Lanka
}

\author{
K.G.D.I. Siriwardana ${ }^{1}$, W.D.P. Weerasinghe ${ }^{1 *}$, G.D.A. Priyantha ${ }^{1}$, K.K.D. Chandrasekara ${ }^{1}$, \\ M.D.N. Rupasinghe ${ }^{1}$, W.R.K.D.W.K.V. Wickramasinghe ${ }^{1}$, I. Dissanayake ${ }^{2}$ and \\ M.R. Wijesinghe ${ }^{2}$
}

\author{
Department of Zoology and Environmental Sciences \\ University of Colombo \\ Sri Lanka
}

\begin{abstract}
Iron toxicity is one of the most commonly observed soil nutritional disorders, which causes lowering of rice yields, especially in the low country wet zone (LCWZ), Sri Lanka. A field screening experiment was conducted in 2017/2018 Maha at regional Rice Research and Development Centre (RRRDC), Bombuwala, Sri Lanka. A site known for its relatively high iron levels was selected for this study. Thirteen rice varieties (eleven new improved and two traditional rice varieties), six advanced breeding lines, four Fe tolerant varieties and a susceptible variety (control) were used. Iron toxicity was scored on a 0 to 9 scale according to standard evaluation system for rice developed by International Rice Research Institute (IRRI) for four growth stages of plants. In addition, soil samples were collected from selected field for physical and chemical analyses. Soil Fe concentration in rice fields ranged from 474.4-1204.7 $\mathrm{mg} / \mathrm{kg}$, which was within the range that could induce toxic effects in rice plants. The degree of leaf bronzing varied significantly across different varieties/lines and in different stages of growth in a single variety/line. Overall results showed that Bg 366, Bg 300 (newly improved rice variety), Madathawalu (a traditional rice variety), $B W$ 14-820 and BW 13-3-1184 (advanced breeding lines) were highly tolerant to Fe toxicity in all four growth stages. Present study emphasized that varieties/lines tolerance to iron toxicity could be cultivated in iron toxicity prevailing soils in LCWZ and used as parental materials in future rice breeding programs in Sri Lanka.
\end{abstract}

Keywords: Field screening, iron toxicity, leaf bronzing score, low country rice

\section{INTRODUCTION}

Rice (Oryza sativa L.), a member of the family Poaceae is widely grown in tropical and subtropical regions. Approximately $90 \%$ of the world's rice is grown in the Asian continent and constitutes the staple food of 3.5 billion people worldwide (El Namaky et al., 2017). In Sri Lanka, rice is the staple food and is cultivated as a lowland crop in most parts of the country. The total land area under rice cultivation is estimated to be around 791,679 ha (Department of Census and Statistics, 2017). However, this total area is not cultivated in every season due to

\footnotetext{
1 Regional Rice Research and Development Centre, Bombuwela, Sri Lanka

2 Department of Zoology and Environmental Sciences, Faculty of Sciences, University of Colombo, Sri Lanka

* Corresponding author: deepika.weerasinghe@yahoo.com
} 
reasons such as delays in the onset of seasonal rains, shortage of irrigation water during the growing season, nutrient toxicity and nutrient deficiency, and the prevalence of diseases.

Iron toxicity is one of the most commonly observed soil nutritional disorders that affect millions of hectares of rice land, especially in South East Asia and West Africa (Becker and Asch, 2005). Excessive amounts of $\mathrm{Fe}^{2+}$ (due to $\mathrm{Fe}$ reduction under anaerobic conditions at low $\mathrm{pH}$ ) have been reported to result significant yield losses ranging from 12 to $100 \%$ depending on the intensity of Fe toxicity and the tolerance of rice genotypes, whereas in the case of acute toxicity, complete crop failure can occur (Audebert and Sahrawat, 2000). The common symptoms of Fe toxicity in rice is called leaf bronzing - brownish red spots which progresses from the tips of lower leaves and spread to the basal parts of the plant, followed by stunting, lowering of tiller number, and the poor development of the root system (Becker and Asch, 2005). In some cases, however, growth and significant yield reduction can be observed without significant leaf bronzing (Sahrawat, 2005). The critical concentration of iron $\left(\mathrm{Fe}^{2+}\right)$ for the development of iron toxicity symptoms varies from as low as 10 to $500 \mathrm{mgL}^{-1}$, depending largely on the nutrient status of the plant and the presence of reduction products (Sahrawat, 2005).

In Sri Lanka, iron toxicity occurs mainly in inland valleys of the low, mid and up country wet zone (Panabokke, 1978), but that in the low country is the most significant. More recent estimations have not been done on the area affected by iron toxicity in Sri Lanka. However, according to Ota (1968) 40,000ha of lowland rice in Sri Lanka is affected by iron toxicity of which 30,000 ha is located in the Low Country Wet Zone (LCWZ). The sandy texture, inadequate soil fertility and low $\mathrm{pH}$ further aggravate this condition. Furthermore, iron toxicity has been observed in Sri Lanka in coastal saline-acid soils, peat soils, acid sulphate soils and other hydromorphic organic soils (Gunathilaka, 1994). In addition, the soils of the inland valleys of the LCWZ are either of alluvial or colluvial origin and chemical properties are related to the associated upland soils. Iron toxicity is a common problem observed in these flat valleys. The presence of soluble iron is related to the subsurface flow conditions, which is also associated with severe deficiency of potassium in the soils (Mapa et al., 1999). Despite the severity of the problem in Sri Lanka, information on iron toxicity in rice is limited. One of the useful mechanisms that would enable us to overcome this problem is to identify varieties of rice that demonstrates tolerance to iron toxicity. Iron toxicity studies using the Leaf Bronzing Score (LBS) as a secondary trait has been conducted on five rice varieties of rice in Sri Lanka (Bentota et al., 2013). The present study is aimed at screening 14 other rice varieties and advanced breeding lines that could be grown in the LCWZ, for iron toxicity using LBS as the end point and to identify their tolerant or susceptible nature at different growth stages of the paddy plant.

\section{METHODOLOGY}

\section{Screening Site}

The experiment was conducted in the rice fields of the Regional Rice Research and Development Centre (RRRDC), Bombuwala, Kalutara District, in the LCWZ of Sri Lanka $\left(6^{\circ} 35^{\prime} 0^{\prime \prime} \mathrm{N}, 80^{\circ} 1^{\prime} 0 " \mathrm{E}\right)$, during $2017 / 2018$ in the Maha season. The soils of the experimental site belonged to the great soil group, Red Yellow Podzolic (RYP) soil (Order: Ultisols, Sub Order: Udults, Great Groups: Rhodudults; Tropudults) (Panabokke, 1996). The minimum and maximum mean seasonal temperatures of the area during the experiment were $22.8 \pm 0.4{ }^{\circ} \mathrm{C}$ and $30.6 \pm 1{ }^{\circ} \mathrm{C}$, respectively. 


\section{Soil Analysis}

Three soil samples from the field (each a composite of at least four subsamples) were taken, from the plough depth $(20 \mathrm{~cm})$ before transplanting (Nugraha et al., 2016). The collected soil was air dried, ground and passed through a $2 \mathrm{~mm}$ sieve to obtain the fine earth fraction. The fine earth fraction was then stored in plastic bags for laboratory analyses. The soil samples were analyzed in the soil laboratory of the regional Rice Research and Development Centre (RRRDC) for soil $\mathrm{pH}$, electrical conductivity, available phosphorus, percentage of organic matter and organic carbon, exchangeable potassium, total iron and soil texture.

The soil $\mathrm{pH}$ and electrical conductivity were measured using an electrometric method (Rhoades et al., 1982). The available phosphorus and percentages of organic matter and organic carbon were measured using the Olsen's method (Olsen et al., 1954) and the Walkley and Black method (Vos et al., 2013), respectively. The exchangeable potassium (Schollenberger and Simon, 1945), soil texture (Ritchey et al., 2015) and total iron (Black, 1965) were also measured. For the measurement of total iron, $5 \mathrm{~g}$ of sieved soil was taken into a $100 \mathrm{ml}$ conical flask containing $50 \mathrm{ml}$ of $\mathrm{NaHCO}_{3}$ buffer solution (pH 8.5). The flask was homogenized for two hours in a mechanical shaker. The solution was then filtered into a 50 ml volumetric flask using a Whatman 1 filter paper. The absorbance of the filtrate was read at $372 \mathrm{~nm}$ (Atomic Absorption Spectrophotometer). A total of 18 samples of soil were analyzed.

\section{Plant Material}

Pure seeds of 13 rice varieties and six advanced breeding lines were collected from the respective research stations. The descriptions of each are given in Table 1. Five rice varieties of known toxicity (Bentota, et al., 2013, Priyantha, et al., 2013) were used as reference material. These include four varieties (Bw 267-3, Bw 372, Bw 364 and Kahata Wee) reported as tolerant and $\mathrm{Bw} 272-6 \mathrm{~b}$ which was reported as susceptible.

\section{Crop establishment}

The land was prepared by impounding water for two weeks after ploughing and harrowing, followed by fine leveling with the help of a wooden leveler. Pure seeds of the 13 rice varieties and six advanced breeding lines (Table 1) were soaked overnight in water and was pregerminated on petri dishes lined with filter paper for $60 \mathrm{~h}$ in a growth chamber (Becker and Asch, 2005). Six-day old seedlings were transplanted as one seedling per hill in $1 \mathrm{~m} \mathrm{x} 1.2 \mathrm{~m}$ plots at a spacing of $20 \mathrm{~cm} \times 20 \mathrm{~cm}$.

\section{Experimental design and trial management}

A Randomized Complete Block Design (RCBD) with three replicates was used in this study. This consisted of 20 plots per replicate, combining the 19 treatments (rice varieties/lines). Fertilizer was applied according to the recommendations given by the Department of Agriculture, Sri Lanka. The water level was constantly maintained at $5 \mathrm{~cm}$ above the soil surface in each block until the end of the trial to create anaerobic conditions favorable for the maintenance of iron in $\mathrm{Fe}^{2+}$ form. The plots were weeded twice to avoid weed infestation. All cultural practices done were according to the recommendations of the Department of Agriculture, Sri Lanka. 
Table 1. The description of Pedigree, site of development, year released, maturity class and reaction to iron toxicity of rice varieties and advanced breeding lines used in this study

\begin{tabular}{|c|c|c|c|c|c|}
\hline Variety Name & Pedigree & $\begin{array}{c}\text { Developed } \\
\text { at }\end{array}$ & $\begin{array}{c}\text { Year } \\
\text { Released }\end{array}$ & $\begin{array}{l}\text { Maturity } \\
\text { (months) }\end{array}$ & $\begin{array}{c}\text { Reaction to } \\
\text { iron toxicity }\end{array}$ \\
\hline Bw 272-6b & $\begin{array}{l}\text { Bw 259-3/ } \\
\text { Bw 240-5-5 }\end{array}$ & Bombuwala & 1981 & 03 & Susceptible $^{2}$ \\
\hline Bg 300 & $\begin{array}{l}\text { Bw 367-7// } \\
\text { IR841/ } \\
\text { Bg 276-5 }\end{array}$ & Batalagoda & 1987 & 03 & Unknown \\
\hline Bw 12-574 & Bw 361/Bw 372 & Bombuwala & (ABL) & 03 & Unknown \\
\hline Bw 13-3-1184 & $\begin{array}{l}\text { Bw 05-1805/ } \\
\text { Bw 04-2012 }\end{array}$ & Bombuwala & (ABL) & 03 & Unknown \\
\hline Bw 13-3-1309 & $\begin{array}{l}\text { At } 07-800 / \\
\text { Bg } 300\end{array}$ & Bombuwala & $(\mathrm{ABL})$ & 03 & Unknown \\
\hline Bw 15-3-1322 & $\begin{array}{l}\text { Bg 96-741/ } \\
\text { IRBB60// } \\
\text { Bg 96-741 } \\
\text { (Bg 455) }\end{array}$ & Bombuwala & $(\mathrm{ABL})$ & 03 & Unknown \\
\hline Bw 267-3 & $\begin{array}{l}\text { Ld 125/ } \\
\text { Bw 248-1 }\end{array}$ & Bombuwala & 1981 & $031 / 2$ & Tolerant $^{1}$ \\
\hline Bw 372 & $\begin{array}{l}\text { Bg 359/ } \\
\text { Bw 267-3 }\end{array}$ & Bombuwala & 2013 & $03 \frac{1}{1 / 2}$ & Tolerant $^{1}$ \\
\hline Bw 364 & $\begin{array}{l}\text { Bw 400/ } \\
\text { O B2552// } \\
\text { Bg } 357\end{array}$ & Bombuwala & 2006 & $03 \frac{1}{1 / 2}$ & Tolerant $^{1}$ \\
\hline At 353 & $\begin{array}{l}\text { [Bg 94-1(Red) x } \\
\text { Bg 400-1] }\end{array}$ & $\begin{array}{l}\text { Ambalantot } \\
\text { a }\end{array}$ & 1992 & $03 \frac{1}{1} 2$ & Unknown \\
\hline Bg 94-1 & IR 262/Ld 66 & Batalagoda & 1975 & $031 / 2$ & Unknown \\
\hline Bg 352 & Bg 380/Bg 367-4 & Batalagoda & 1992 & $03 \frac{1}{2}$ & Unknown \\
\hline Bg 360 & $\begin{array}{l}\text { 84-3346/IR36/ } \\
\text { Senerang }\end{array}$ & Batalagoda & 1999 & $03 \frac{1}{1 / 2}$ & Unknown \\
\hline Bg 366 & $\begin{array}{l}\text { Bg 300/94- } \\
\text { 2236// } \\
\text { Bg 300/Bg } 304\end{array}$ & Batalagoda & 2009 & $03 \frac{1}{2}$ & Unknown \\
\hline Bg 359 & $\begin{array}{l}88-5089-\mathrm{Bg} 379- \\
2\end{array}$ & Batalagoda & 1999 & $03 \frac{1}{1} 2$ & Unknown \\
\hline Bw 14-820 & $\begin{array}{l}\text { Bw 361/ } \\
\text { Bw 15-1621 } \\
(\text { Bw372) }\end{array}$ & Bombuwala & $(\mathrm{ABL})$ & $03 \frac{1}{1 / 2}$ & Unknown \\
\hline Bw 13-1106 & $\begin{array}{l}\text { Bw 451/ } \\
\text { Bg 07-1350 }\end{array}$ & Bombuwala & $(\mathrm{ABL})$ & $03 \frac{1}{1 / 2}$ & Unknown \\
\hline Kahata Wee & $\begin{array}{l}\text { (traditional rice } \\
\text { variety) }\end{array}$ & - & - & $4-41 / 2$ & Tolerant $^{1}$ \\
\hline Madathawalu & $\begin{array}{l}\text { (traditional rice } \\
\text { variety) }\end{array}$ & - & - & $4-41 / 2$ & unknown \\
\hline
\end{tabular}

${ }^{2}$ Bentota, et al., 2013, ${ }^{2}$ Priyantha, et al., 2013

ABL: Advanced Breeding Line 


\section{Data collection}

Data were collected from each plot. Ten plants from the centre of the plot were used for measurements during the four growth stages 2 to 5 (2 - seedling, 3 - tillering, 4 -stem elongation, 5-booting). A standard evaluation system for rice i.e. the Leaf Bronzing Score (LBS), developed by the International Rice Research Institute (IRRI, 2014) was used to score the symptoms of iron toxicity. Visual leaf symptoms were scored by assigning a score from 0 to 9 to each of the leaves affected by bronzing (Table 2).

Table 2. Standard Evaluation System for assessing Leaf Bronzing (Source IRRI, 2014)

\begin{tabular}{cl}
\hline Scale Value & \multicolumn{1}{c}{ Observations } \\
\hline 1 & $\begin{array}{l}\text { Growth and tillering nearly normal } \\
\text { Growth and tillering nearly normal: reddish brown spots or orange } \\
\text { discoloration on tips of older leaves } \\
\text { Growth and tillering nearly normal: older leaves reddish brown, purple or } \\
\text { orange yellow }\end{array}$ \\
5 & $\begin{array}{l}\text { Growth and tillering retarded: many leaves discolored } \\
7\end{array}$ \\
9 & Growth and tillering ceases: most leaves discolored or dead \\
\hline
\end{tabular}

\section{Statistical analysis}

A One-way ANOVA was used to ascertain if there were significant differences in the Leaf Bronzing Scores (Log transformed) between rice varieties/lines, as well as between the different stages of the growth cycle. All values are shown as the mean of three replicates, and the mean was calculated. The results were analyzed using the Minitab statistical analysis package (version 17) to determine significant differences. Further, grouping of rice varieties based on the degree of leaf bronzing (and hence the degree of tolerance or susceptibility) was examined using the complete linkage hierarchical cluster analysis for all four growth stages.

\section{RESULTS AND DISCUSSION}

\section{Soil characteristics within the experimental site}

Soil characteristics within the experimental site are shown in Table 3. According to the recommendations made by the Department of Agriculture (Sri Lanka) for ideal paddy soil nutrient conditions in the LCWZ, it is evident that the soil within the experimental site had relatively low electrical conductivity, low in exchangeable potassium $(\mathrm{K})$, moderately rich in both organic matter and organic carbon, and moderate in phosphorous (P). The soil was sandy loam in terms of texture and contained a high sand content, but is poorly drained (Panabokke, 1996). It is clear that the soil had high reserve acidity (indicated by $\mathrm{pH}$ in soil solution). These conditions promote soil reduction resulting in an increased iron concentration in the soil solution.

The results show that $\mathrm{Fe}$ (II) concentrations in the soil solution is in the range of 474.4 $1204.7 \mathrm{mg} / \mathrm{kg}$, levels which are capable of inducing toxicity in certain varieties of rice (Sahrawat, 2005). The levels of Fe (II) over 18 weeks during which the trials were conducted, is shown in Figure 1. It is seen that in this gently sloping site, the contribution of Fe (II) through 
the interflow is low and less important than the release of the Fe (II) in-situ. This is one of the reasons for iron toxicity in LCWZ soils in Sri Lanka. Additionally, low K is generally associated with high iron concentrations and hence high iron toxicity (Sahrawat, 2005). This is why iron toxicity in lowland rice is often associated with $\mathrm{K}$ deficiency. In this field experiment, rice plants growing on the Ultisols within the experimental site showed severe iron toxicity symptoms (Table 3 ). The soil analysis shows that the soils, although relatively high in iron, is low in nutrients, especially $\mathrm{K}$ and P. Such multiple deficiency stress factors may have enhanced leaf bronzing, as shown in other studies (Audebert and Sahrawat, 2000). Often susceptibility to toxicants increase in the face of additional stresses (Sahrawat, 2005).

Table 3. Soil Characteristics of an iron toxic Ultisol in the experimental site Bombuwala, Sri Lanka

\begin{tabular}{lcc}
\hline Soil Parameter & Range & Mean \pm St. Dev. \\
\hline Total Iron $(\mathrm{mg} / \mathrm{kg})$ & $474.4-1204.7$ & $786.75 \pm 47.15$ \\
PH (soil solution) & $4.15-5.01$ & $4.54 \pm 0.21$ \\
EC $(\mathrm{mS} / \mathrm{m})$ & $0.07-0.25$ & $0.18 \pm 0.04$ \\
Organic Carbon $(\%)$ & $3.14-7.79$ & $4.48 \pm 2.22$ \\
Organic Matter $(\%)$ & $5.43-13.49$ & $7.75 \pm 3.85$ \\
K $(\mathrm{ppm})$ & $76.50-79.10$ & $77.67 \pm 1.42$ \\
P $(\mathrm{ppm})$ & $5.07-11.06$ & $7.89 \pm 2.46$ \\
\hline
\end{tabular}

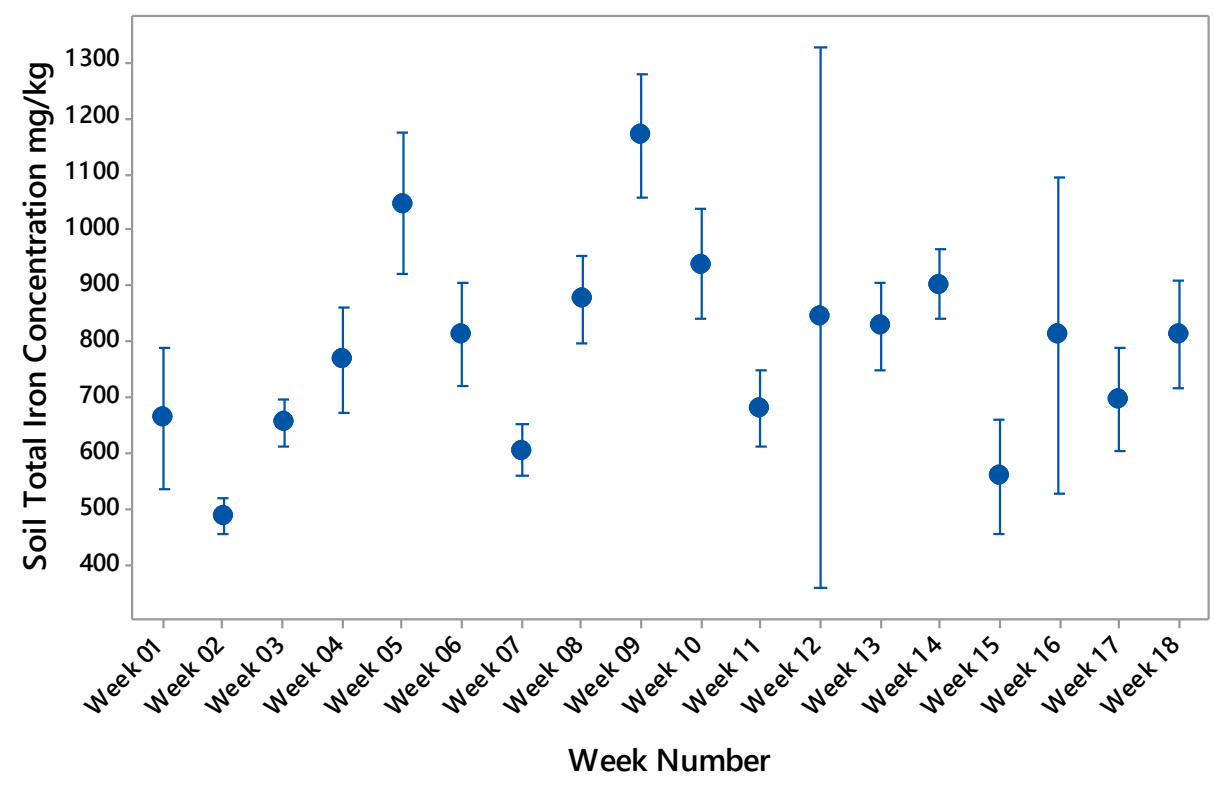

Figure 1. Variation in Fe concentrations in the experiment field at RRRDC, Bombuwala over an 18-weeks trial period 
The present study attempted to assess the efficacy of iron toxicity tolerance screening based on the Leaf Bronzing Score, in an area that is known for high Fe toxicity (a hot spot). Some important findings of the study with respect to iron toxicity as inferred by leaf bronzing scores (LBS) have been discussed below.

\section{Performance of rice varieties under natural iron toxicity conditions}

In this field experiment, rice plants growing on the Ultisols at the experimental site showed severe iron toxicity symptoms as depicted in Figure 2. However, based on the analysis of the mean LBS values i.e. pooling the LBS values for all the four growth stages in a given variety, (Table 4), it was evident that there were highly significant differences among rice varieties in terms of the LBS values and hence in the apparent levels of susceptibility or tolerance to iron toxicity under natural conditions (One-way Anova $\mathrm{F}=99.12, \mathrm{P}<0.001$ ). The lowest overall mean LBS (mean LBS-1.07-1.83, growth and tillering nearly normal) values for all stages were recorded in Kahata wee, Bw 364, Madathawalu, Bw 13-31184, Bw 267-3, Bw 372, Bw 14$820, \mathrm{Bg} 366$ and $\mathrm{Bg} 300$ which suggests that these varieties are naturally, relatively more tolerant to iron toxicity than the other varieties (Figure 2) (Table 04). Based on the scale of the standard evaluation system of iron toxicity used in the present study these seven rice varieties and two advanced breeding line could be classified as being 'Highly Tolerant/Tolerant' to iron toxicity. On the other hand, the highest mean LBS recorded in, Bg 359 (mean LBS- 5.39, growth and tillering retarded) and Bw 272-6b (mean LBS- 5.00, growth and tillering retarded) would allow it to be categorized as being 'Highly Susceptible/Susceptible'. The nature of tolerance in the other rice varieties varied between these two extremes and is categorized as 'Moderately Tolerant', and 'Moderately Susceptible' conditions.

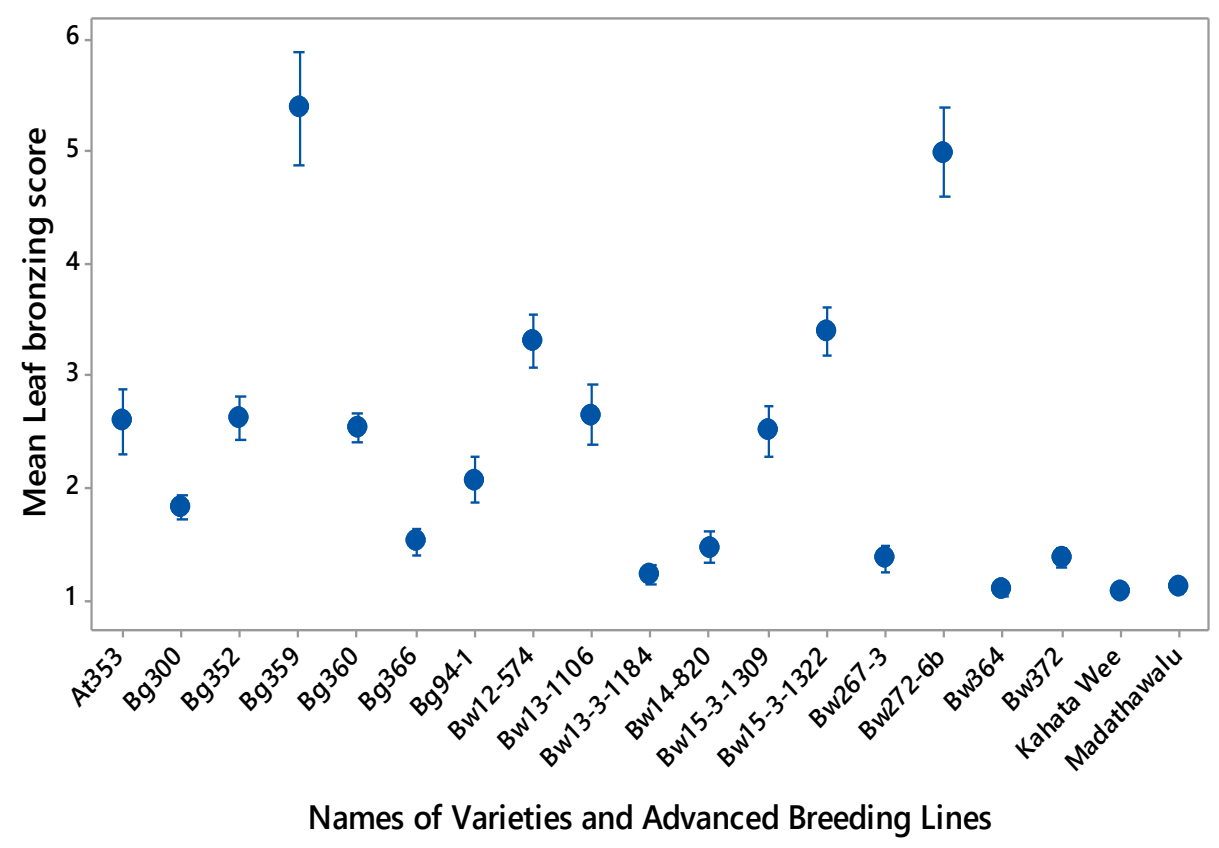

Figure 2. Variation in the mean leaf bronzing scores in the tested rice varieties and advanced breeding lines for all four growth stages 
Table 4. Mean leaf bronzing scores in the tested rice varieties and advanced breeding lines for all the four growth stages

\begin{tabular}{lclc}
\hline $\begin{array}{c}\text { Varieties and } \\
\text { Advanced } \\
\text { Breeding Lines }\end{array}$ & $\begin{array}{c}\text { Leaf Bronzing } \\
\text { Score } \\
\text { Mean } \pm \text { St.Dev. }\end{array}$ & $\begin{array}{c}\text { Varieties and } \\
\text { Advanced } \\
\text { Breeding Lines }\end{array}$ & $\begin{array}{c}\text { Leaf Bronzing } \\
\text { Score } \\
\text { Mean } \pm \text { St.Dev. }\end{array}$ \\
\hline Kahata Wee & $1.07 \pm 0.26$ & Bw 13-3-1309 & $2.50 \pm 1.30$ \\
Bw 364 & $1.10 \pm 0.30$ & Bg 360 & $2.54 \pm 0.70$ \\
Madathawalu & $1.12 \pm 0.33$ & At 353 & $2.60 \pm 1.60$ \\
Bw 13-3-1184 & $1.22 \pm 0.47$ & Bg 352 & $2.62 \pm 1.04$ \\
Bw 267-3 & $1.36 \pm 0.61$ & Bw 13-1106 & $2.65 \pm 1.48$ \\
Bw 372 & $1.38 \pm 0.50$ & Bw 12-574 & $3.30 \pm 1.28$ \\
Bw 14-820 & $1.47 \pm 0.74$ & Bw 15-3-1322 & $3.40 \pm 1.16$ \\
Bg 366 & $1.52 \pm 0.60$ & Bw 272-6b & $5.00 \pm 2.18$ \\
Bg 300 & $1.83 \pm 0.58$ & Bg 359 & $5.39 \pm 2.80$ \\
Bg 94-1 & $2.07 \pm 1.10$ & & \\
\hline
\end{tabular}

It was interesting that the results obtained with respect to the performance of $\mathrm{Bg} 359$ in the present study, contradicted previous reports by Priyantha et al., (2013). In the present study, Bg 359 showed a susceptible nature to iron toxicity (mean LBS- 5.39, growth and tillering retarded), while Priyantha et al., (2013) documents that this variety is tolerant. Probable reasons for this disparity may be the soil heterogeneity or the Genotype $\times$ Environment interactions $(\mathrm{GxE})$. High variability in the distribution of Fe, even in the same field, resulting in large environmental errors and large $\mathrm{G} \times \mathrm{E}$ interactions on rice yield greatly impairs varietal selection and breeding efficiency for tolerance to iron toxicity (Cherif et al., 2009). Therefore, research on iron toxicity should be directed to the biophysical environmental analysis and multi locational trials prior to their establishment (Piepho, 1996).

Early studies report that traditional rice varieties, in comparison to improved varieties, demonstrate a greater tolerance to iron toxicity, when cultivated on high $\mathrm{Fe}$ soils (Gunawardana, 1982). However, Bentota and Weerasingha (2005) have shown varying degrees of iron toxicity tolerance in some traditional rice varieties and further confirmed that Kahata wee, which demonstrated high tolerance, was the most promising traditional rice variety for Fe high soils in Sri Lanka. In our study, in addition to Kahata wee, another traditional rice variety - Madathawalu, was also recorded as being highly tolerant to the iron toxicity, indicating its potential to be used as a donor of iron toxicity tolerance genes in future rice variety improvement programs in Sri Lanka. Furthermore, in our field screening the four advanced breeding lines, $\mathrm{Bw}$ 13-3-1184, Bw14-820, Bw 13-3-1309 and $\mathrm{Bw}$ 13-1106 also exhibited high tolerance/tolerance to iron toxicity. Thus, these four lines could also be used as parental lines in future breeding programs in Sri Lanka.

\section{Variation of Leaf Bronzing Scores (LBS) at different growth stages}

The one-way ANOVA confirmed that the differences in LBS values across the growth stages in the 19 tested rice varieties/lines were highly significant $(\mathrm{F}=165.62, \mathrm{P}<0.001)$. According to Figure 3 and Table 5, the LBS values in given rice varieties and advanced breeding lines varied considerably across the different growth stages, and therefore showed variation in the degree of tolerance to iron toxicity throughout the growth cycle. In the seedling stage (GS - 2), the mean LBS values ranged from $1-3.2$. The lowest mean LBS $(<2)$ was recorded in eleven of the rice varieties - Bw 267-3, Bw 372, Bw 364, Kahata Wee, Bg 94-1, At 353, Bg 352, Bg 300, Bg 360, Bg 366, Madathawalu and the three advanced breeding lines Bw13-1106, Bw13- 
3-1184, Bw13-3-1309 suggesting tolerance at the seedling stage (growth and tillering nearly normal). The highest mean LBS (3.2), was observed in the advanced breeding line Bw15-51322 showing that the seedlings of this line was susceptible but the growth and tillering was nearly normal with older leaves reddish brown, purple or orange yellow. During the tillering stage (GS-3), the mean LBS values also varied from 1.1-3.4, indicating a similar degree of toxicity as that demonstrated in the seedling stage. However, here the varieties that showed moderate tolerance were different to those of the seedling stage and included the two varieties - Bg 272-6b and Bg 359, which was tolerant to iron toxicity (LB-2) during the seedling stage.

There was greater variation among the varieties in mean LBS values at the stem elongation stage (GS-4), ranging from 1 to 7. The rice varieties Bw 267-3, Bw 372, Bw 364, Kahata wee Madathawalu and the advanced breeding lines $\mathrm{Bw} 13-3-1184$ and $\mathrm{Bw} 14-820$ showed the lowest mean LBS value $(<2)$, suggesting their highly tolerant nature to iron toxicity under natural field conditions. Whereas, Bw 359 (6.86) and Bw 272-6b (7) with the highest mean LBS value), demonstrated that it is susceptible to iron toxicity during the stem elongation stage. Interestingly the rice variety At 353 and the advanced breeding lines Bw 12-574, Bw131106, and Bw13-3-1309, which were previously shown to be tolerant to iron toxicity, both during the seedling and tillering stages, become moderately tolerant/susceptible to iron toxicity (mean LBS 3.5-4.13), during the later stage of its growth.

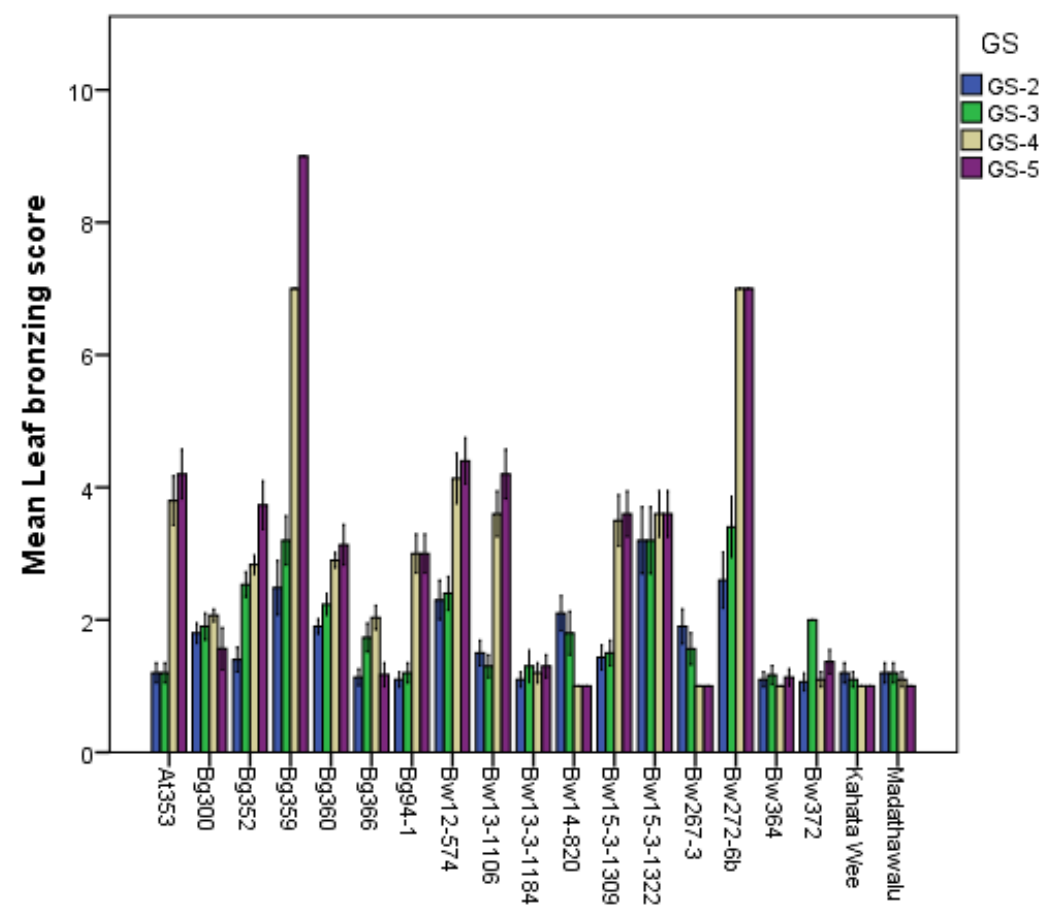

Names of Varieties and Advanced breeding lines

Figure 3. Mean Leaf Bronzing Scores across different growth stages in the tested rice varieties and advanced breeding lines (Error bars show 95\% confidence intervals) 
In the final stage of monitoring, i.e. during the booting stage (GS-5), mean LBS values differed extensively between rice varieties ranging from 1 to 8.93. The highest mean LBS value (mean LBS -8.93) was seen in Bg 359 (resulting in the death of all plants), thereby demonstrating that it was highly susceptible to iron toxicity. The varieties, Bw 267-3, Bw 372, Bw 364, Kahata Wee, Bg 300 Bg 366, Madathawalu, and the advanced breeding lines Bw 13-3-1184, $\mathrm{Bw} 14-820$ once again showed a highly tolerant nature (mean LBS $<2$ ).

The assessment of the degree of iron toxicity as interpreted by the mean LBS values over the four growth stages in the 13 rice varieties and 6 advanced breeding lines are shown in Table 5. Making an overall assessment, it could be inferred from the leaf bronzing symptoms across the different growth stages of the paddy cycle, that Bw 267-3, Bw 372, Bw 364, Kahata Wee, Bg 300, Bg 366, Bw 13-3-1184, Bw 14-820 and Madathawalu, exhibiting low mean LBS values from the seedling (GS-2) through to the booting stage (GS-5) reveals the greatest tolerance to iron toxicity, in comparison to the other rice varieties.

Table 5. Degree of Fe tolerance and mean LBSat different growth stages in the tested rice varieties and advanced breeding lines under field conditions.

\begin{tabular}{|c|c|c|c|c|c|c|c|c|}
\hline \multirow{3}{*}{$\begin{array}{l}\text { Rice } \\
\text { Variety/line }\end{array}$} & \multicolumn{8}{|c|}{ Growth Stage } \\
\hline & \multicolumn{2}{|c|}{ Seedling } & \multicolumn{2}{|c|}{ Tillering } & \multicolumn{2}{|c|}{ Stem elongation } & \multicolumn{2}{|c|}{ Booting } \\
\hline & $\begin{array}{l}\text { Reaction } \\
\text { to Fe } \\
\text { toxicity }\end{array}$ & $\begin{array}{l}\text { Mean } \\
\text { LBS } \\
\text { value }\end{array}$ & $\begin{array}{l}\text { Reaction } \\
\text { to Fe } \\
\text { toxicity }\end{array}$ & $\begin{array}{l}\text { Mean } \\
\text { LBS } \\
\text { value }\end{array}$ & $\begin{array}{l}\text { Reaction } \\
\text { to Fe } \\
\text { toxicity }\end{array}$ & $\begin{array}{l}\text { Mean } \\
\text { LBS } \\
\text { value }\end{array}$ & $\begin{array}{l}\text { Reaction } \\
\text { to Fe } \\
\text { toxicity }\end{array}$ & $\begin{array}{l}\text { Mean } \\
\text { LBS } \\
\text { value }\end{array}$ \\
\hline Bw 267-3 & HT & 1.9 & HT & 1.6 & HT & 1 & HT & 1 \\
\hline Bw 372 & HT & 1 & $\mathrm{~T}$ & 2 & HT & 1.1 & HT & 1.36 \\
\hline Bw 364 & HT & 1.1 & HT & 1.16 & HT & 1 & HT & 1.13 \\
\hline Kahata Wee & HT & 1.2 & HT & 1.1 & HT & 1 & HT & 1 \\
\hline Bg 94-1 & HT & 1.1 & HT & 1.2 & MT & 3 & MT & 3 \\
\hline Bw 272-6b & $\mathrm{T}$ & 2.6 & MT & 3.4 & $\mathrm{~S}$ & 7 & S & 7 \\
\hline At 353 & HT & 1.2 & HT & 1.2 & MT & 3.8 & MS & 4.2 \\
\hline Bg 352 & HT & 1.4 & $\mathrm{~T}$ & 2.53 & $\mathrm{~T}$ & 2.83 & S & 5 \\
\hline Bg 300 & HT & 1.8 & HT & 1.9 & $\mathrm{~T}$ & 2.06 & HT & 1.56 \\
\hline Bg 360 & HT & 1.7 & $\mathrm{~T}$ & 2.23 & $\mathrm{~T}$ & 2.9 & MT & 3.13 \\
\hline Bg 366 & HT & 1.13 & HT & 1.73 & $\mathrm{~T}$ & 2.03 & HT & 1.2 \\
\hline Bg 359 & $\mathrm{~T}$ & 2.5 & MT & 3.2 & $\mathrm{~S}$ & 6.86 & HS & 8.93 \\
\hline Bw 12-574 & $\mathrm{T}$ & 2.3 & $\mathrm{~T}$ & 2.4 & MS & 4.13 & MS & 4.4 \\
\hline Bw 13-3-1184 & HT & 1.1 & HT & 1.3 & HT & 1.2 & HT & 1.3 \\
\hline Bw 14-820 & $\mathrm{T}$ & 2.1 & HT & 1.8 & HT & 1 & HT & 1 \\
\hline Bw 13-3-1309 & HT & 1.43 & HT & 1.5 & MT & 3.5 & MT & 3.6 \\
\hline Bw 13-3-1322 & MT & 3.2 & MT & 3.2 & MT & 3.6 & MT & 3.6 \\
\hline Bw 13-1106 & HT & 1.5 & HT & 1.3 & MT & 3.6 & MS & 4.2 \\
\hline Madathawalu & HT & 1.2 & HT & 1.2 & HT & 1.1 & HT & 1 \\
\hline
\end{tabular}

HT: Highly Tolerant, T: Tolerant, MT: Moderately Tolerant, MS: Moderately Susceptible, S:

Susceptible, HS:Highly Susceptible 


\section{Genetic variations in the selected rice varieties under iron toxicity conditions}

Improvement of crop varieties will only be successful in the presence of high genetic variation and the heritability of desirable traits (Ravi et al., 2003). Therefore, for establishing relationships among different varieties, assessment of genetic variability has become increasingly necessary (Kibria et al., 2009). The Cluster analysis performed on the data in the present study classified the rice varieties into two main groups (Group A and B) which was based on the complete linkage correlation coefficient distances according to the observed variation in the mean Leaf Bronzing Score values (Figure 4).

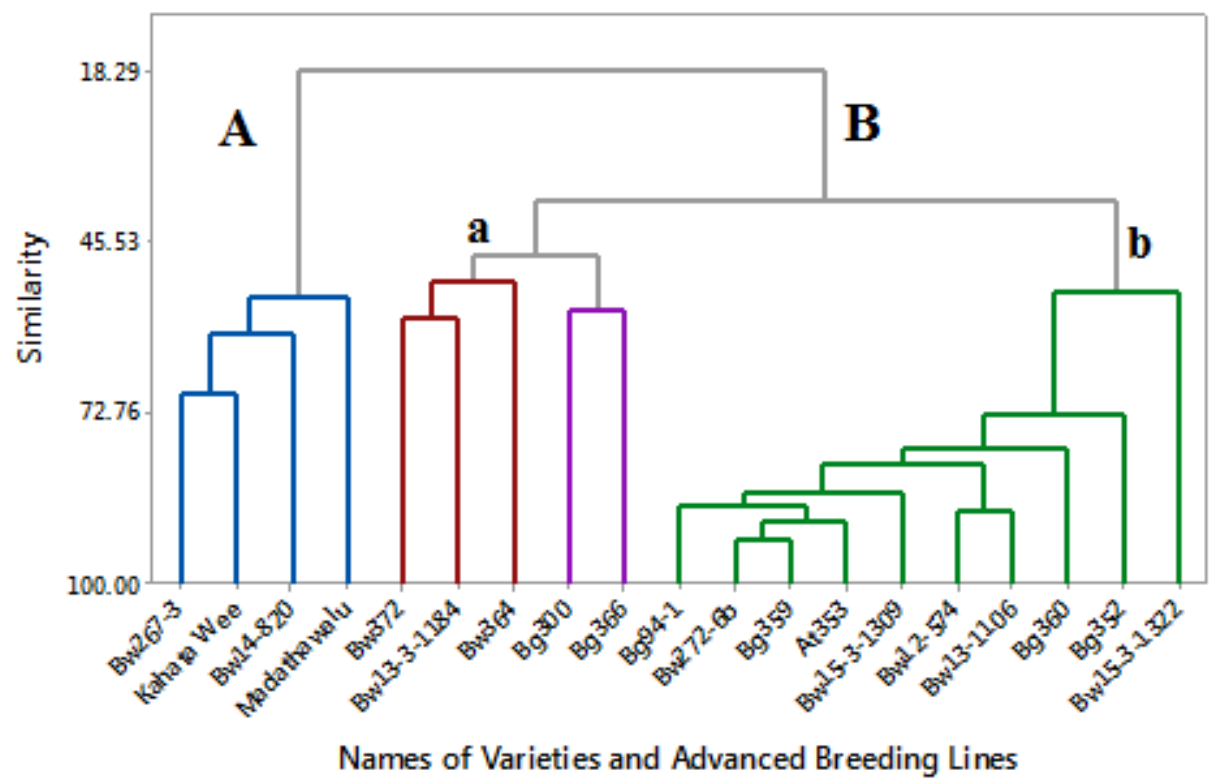

\section{Figure 4. Clustering of the 19 tested rice varieties/lines based on the observed mean leaf bronzing score for all four growth stages}

Based on the $80 \%$ dissimilarity level, Group A was subdivided into four groups of rice varieties/lines (Bw 267-3, Kahata Wee, Bw 14-820, Madathawalu). Group B was subdivided into two sub groups (a - Bw 372, Bw 13-3-1184, Bw 364, Bg 300, Bg 366) (b - Bg 94-1, Bw 272-6b, Bg 359, At 353, Bw 15-3-1309, Bw 12-574, Bw 13-1106, Bg 360, Bg 352, Bw 15-31322). In the dendrogram susceptible varieties/lines of any growth stages were well separated from that of the highly tolerant varieties/lines. The results obtained from the cluster analyses indicated that the LBS were of importance in differentiating rice varieties/lines to the reaction of iron toxicity as well as to assess the diversity among them.

It is evident that based on Figure 4, the most diversified cluster is A which consists of four rice varieties/lines divulging that the selected character (Leaf bronzing score at different growth stages) in this cluster was considerably different to those of the other varieties. The closer the clusters, which are lesser, separated by distance, indicates lesser variation in the degree of leaf bronzing (and hence could be interpreted as lesser genetic variation) suggesting that they may be from same parental stock. 
Rice varieties in Group A with the lowest mean LBS values (mean LBS 1) showed the highest tolerance to iron toxicity. Even within this cluster the variety Bw267-3 was far separated from Madathawalu, the former being the most tolerant to iron toxicity. Rice varieties/lines which were tolerant/susceptible to iron toxicity at any stages were clustered in to Group B (mean LBS >1). Rice varieties in the Subgroup 'a' showed tolerance with mean LBS of 2-1, any growth stages which indicate that growth and tillering was nearly normal with reddish brown spots or orange discoloration on tips of older leaves.

The rice varieties with mean LBS of 3-8.93 at any growth stages were grouped as Subgroup 'b' and within this subgroup "Bw 272-6b and Bg 359" and "Bw 12-574 and Bw 13-1106" were more similar to each other than the others. In addition subgroup $b$, was the most diverse and included the rice varieties exhibiting mean LBS values of 3-8.93 at any growth stage, being categorized as susceptible to highly susceptible to the iron toxicity.

\section{CONCLUSIONS}

The soil analyses conducted during the present study shows that in the LCWZ of Sri Lanka, iron toxicity may be a physiologically complex nutritional disorder which may be synergistically enhanced by deficiencies of several other nutrients, especially of $\mathrm{K}, \mathrm{P}$ and organic matter, which could also be implicated as contributing to the occurrence of Iron toxicity symptoms in rice grown on these soils. The present study revealed that of the 13 varieties of rice and six advanced breeding lines evaluated for iron toxicity under natural field conditions at the experimental site at Bombuwala, Sri Lanka, only seven varieties and two advanced breeding line (Kahata wee, Bw 364, Madathawalu, Bw 13-31184, Bw267-3, Bw $372, \mathrm{Bw} 14-820, \mathrm{Bg} 366$ and $\mathrm{Bg} 300$ ) exhibited satisfactory tolerance levels to iron toxicity. Further, the traditional rice variety - Madathawalu and the two advanced breeding lines Bw14-820 and Bw13-3-1184, were confirmed to possess a highly tolerant trait to iron toxicity, showing that these varieties could be utilized as parental material in rice breeding program in Sri Lanka, to develop iron toxicity tolerant rice varieties. Furthermore, our findings suggest that leaf bronzing symptoms can occur at different growth stages which in turn may affect plant growth at seedling, tillering, stem elongation and booting stages. However, tolerant rice varieties and advanced breeding lines exhibiting low LBS values throughout their growth cycle indicate the greatest potential source to overcome iron toxicity.

\section{REFERENCES}

Audebert, A. and Sahrawat, K.L. (2000). Mechanisms of iron toxicity in lowland rice. J. Plant Nutr. 23, 1877-1885.

Becker, M. and Asch, F. (2005). Iron toxicity in rice-conditions and management concepts. J.PlantNutr. Soil Sci.168, 558-573.

Bentota, A.P. and Weerasinghe, B.G.D.S. (2005). Iron toxicity tolerance in some traditional rice varieties of Sri Lanka, Annals of the Sri Lanka Department of Agriculture, Peradeniya, Sri Lanka. 7:337-340.

Bentota, A.P., Faheim, M., Weerasinghe, B.G.D.S., Paranagama, C.A. and Jayathilaka. T.N.A.W. (2013). Development and performance of released rice varieties to iron toxic rice soils in Sri Lanka. Tropical Agriculturist. 161, 1-18. 
Black, C. A. (ed.) 1965; Method of Soil Analysis, Part 2, Chemical and Microbiological Properties, American Society of Agronomy, Inc, Publisher, Madison, Wisconsin USA. pp.301307.

Cherif, M., Fofana, M., Audebert, A. and Zouzou, Z. (2006). Significant aspects of iron toxicity in West Africa. In A. Audebert, L. T, Narteh, P. Kiepe, D. Millar and B. Beks eds., Iron toxicity in rice based system in West Africa. WARDA, Cotonou. pp 141-148

Department of Census and Statistics. (2017). http://www.statistics.gov.lk

El-Namaky, R., Bare Coulibaly, M.M., Alhassan, M., Traore, K., Nwilene, F., Dieng, I., Ortiz, R., Manneh, B. (2017). Putting Plant Genetic Diversity and Variability at Work for Breeding, Hybrid Rice Suitability in West Africa. Diversity, 9, 27.

Gunathilaka, G.A. (1994). Rice production in relation to iron toxic soils in Sri Lanka. Rice and problem soils in South and Southeast Asia: Senadhira, D., Ed.; International Rice Research Institute: Manila, Philippines, 109-114; IRRI Discussion Paper Series No. 4.

Gunawardena, S.D.I.E. (1982). Rice breeding for tolerance to problem soils. Tropical Agriculturist. 138, 1-30

IRRI. (2014). Standard Evaluation System for rice, $5^{\text {th }}$ ed. International Rice Research Institute, P.O.Box 933, Manila, Philippines. pp 35.

Kibria, K., Nur, F., Begum, S.N., Islam, M.M., Paul, S.K., Rahman, K.S, and Azam, S.M.M. (2009). Molecular marker based genetic diversity analysis in aromatic rice genotypes using SSR and RAPD markers. Int. J. Sustain. Crop Prod. 4, 23-34.

Mapa, R.B., Somasiri, S. and Nagarajah, S. (1999). Soils of the Wet Zone of Sri Lanka. Morphology, Characterization and Classification. Soil Science Society of Sri Lanka. 184p.

Nugraha, Y., Ardie, S.W., Suwaino, Ghulamahdi, M. and Aswidinnoor, H. (2016). Implication of Gene Action and Heritability under stress and control conditions for selection iron toxicity tolerant in rice. AGRIVITA Journal of Agricultural Science. 38(3), 282-295.

Olsen, S. R., Cole, C. V., Watanabe, F. S. \& Dean. L. A. (1954). Estimation of available phosphorus in soils by extraction with NaHCO3, USDA Cir.939. U.S. Washington.

Ota, Y., (1968). Studies on the occurrence of the physiological disease called 'bronzing'. Bull Natl Inst Agric Sci (Japan) D. 18: 31-104.

Panabokke, C.R. (1978). Rice soils of Sri Lanka. In soils and rice. International Rice Research Institute, Los Banos, Philippines Pages 22-33

Panabokke, C. R. (1996). Soils and agro-ecological environments of Sri Lanka. Colombo: Natural Resources, Energy and Science Authority of Sri Lanka.

Piepho, H. P. (1996). Analysis of genotype-environment interaction and phenotypic stability. In M. S. Kang \& H. G. Gauch Jr. (Eds.), Genotype-by-environment interaction (pp. 151-174). Boca Raton, FL: CRC Press. http://dx.doi.org/10.1201/9781420049374 
Priyantha, G. D. A., Weerasinghe, B. G. D. S. and Rasanjali, K. A. C. (2013). Iron toxicity tolerance of improved rice varieties in the low country wet zone of Sri Lanka. Proceedings of the International Symposium on Agriculture and Environment, University of Ruhuna, Sri Lanka pp.428-432 ref.5

Ravi, M., Geethanjali, S., Sameeyafarheen, F. and Maheswaran, M. (2003). Molecular marker based genetic diversity analysis in rice(Oryza sativa L.) using RAPD and SSR markers. Euphytica. 133, 243-252.

Ritchey, Edwin L., McGrath, Joshua M. and Gehring, David. (2015). Determining soil texture by feel. Agriculture and Natural Resources Publications. 139.

Rhoades, J. D. (1982). Soluble salts. p. 167-179. In: A. L. Page et al. (ed.) Methods of soil analysis: Part 2: Chemical and microbiological properties. Monograph Number 9 (Second Edition). ASA, Madison, WI.

Sahrawat, K.L. (2005). Iron toxicity in wetland rice and the role of other nutrients. J.PlantNutr. 27, 1471-1504.

Salim, M., Akram, M., Akhtar, M.E. and Ashraf, M. (2003). Rice, A production hand book. Pakistan Agricultural Research Council, Islamabad. pp.70.

Schollenberger, C.J. and Simon R.H. (1945). Determination of Exchangeable Capacity and Exchangeable Bases in the Soil-Ammonium Acetate Method. Soil Sci. Res., 14, 161-168

Vos M, olf AB, Jennings SJ, Kowalchuk GA. (2013). Micro-scale determinants of bacterial diversity in soil. FEMS Microbiol Rev. 37, 936-954. 